\title{
EFEKTIVITAS LATIHAN BODYWEIGHT TRAINING DENGAN METODE TABATA UNTUK MENINGKATKAN KEBUGARAN JASMANI MAHASISWA BARU TAHUN 2016-2017 PENDIDIKAN KEPELATIHAN OLAHRAGA FKIP UNIVERSITAS PGRI ADI BUANA SURABAYA
}

\author{
Brahmana Rangga P, Ismawandi Bripandika Putra \\ Universitas PGRI Adi Buana Surabaya
}

\begin{abstract}
Bodyweight training using Tabata method is used as an alternative to keep physical fitness in a short duration. The research on the effectiveness of bodyweighty training using Tabata method to improve physical fitness of new students of 2016-2017 academic year in Sport Coaching Education Department, Faculty of Teacher Training and Education, University of PGRI Adibuana Surabaya. The purpose of this research is to give students solution to improve and maintain their physical fitness condition that they can perform daily activities maximally. This is an experimental research using one groups pre-test-post-test design, where pretest is given before treatment and posttest after the treatment. The instruments of this research are; MFT (Multistage Fitness Test) to know $\mathrm{VO}_{2}$ max, and test of endurance and muscle strength including: (1) sit up and pull up test; (2) grip strength test, used to measure the hand muscles; (3) back dynamometer, used to measure the back muscles strength; and (4) leg dynamometer, used to measure leg muscle strength.

The data analysis technique uses t-test. T-test statistical analysis is conducted to find out whether there is a significant improvement in bodyweight training using Tabata method to improve new students' physical fitness in 2016-2017 academic year. The result of the research shows that $H_{o}$ (Null hypothesis) is accepted, with score of $-6,99192<2,04523$. The score of $F_{\text {observed }}$ is -6,99192 in which Critical score of two-tail (t-table) is 2.04523. Thus, it shows that $H_{o}$ (Null hypothesis) is accepted, meaning bodyweight training using Tabata method is effective to improve physical fitness of sport coaching education department students in faculty of teacher training and education, University of PGRI Adibuana Surabaya. Therefore, it can be concluded that bodyweight training using Tabata method can improve physical fitness of sport coaching education department students in faculty of teacher training and education, university of PGRI Adibuana Surabaya.
\end{abstract}

Keywords: Bodyweight Training, Tabata Method, Physical Fitness

Bodyweight training dengan metode tabata digunakan sebagai alternatif untuk aktifitas fisik agar kebugaran jasmani terjaga tanpa harus menggunakan durasi waktu yang panjang. Penelitian tentang efektifitas latihan bodyweighty training dengan menggunakan metode tabata untuk meningkatkan kebugaran jasmani dilakukan pada mahasiswa baru angkatan 2016-2017 Pendidikan Kepelatihan Olahraga, Fakultas Keguruan Ilmu Pendidikan, Universitas PGRI Adibuana Surabaya. Melalui penelitian ini diharapkan mampu memaksimalkan dan sekaligus memberi solusi kepada mahasiswa untuk dapat selalu melakukan aktifitas fisik agar dapat meningkatkan dan menjaga kondisi kebugaran jasmani sehingga mahasiswa mampu melakukan aktifitas sehari-hari dengan maksimal dan lebih berkualitas. Penelitian ini menggunakan eksperimen dengan desain penelitian yang digunakan dalam penelitian yaitu one groups pretest-posttest design, desain penelitian yang terdapat pretest sebelum diberi perlakuan dan posttest setelah diberi perlakuan. Instrumen penelitian yang digunakan yaitu: MFT (Multistage Fitness Test) untuk mengetahui VO2Max, tes daya tahan dan kekuatan otot meliputi: (1). tes sit up, pull up, (2). Grip strength tes, 
digunakan untuk mengukur otot-otot tangan, (3). back dynamometer, digunakan untuk mengukur kekuatan otot punggung, (4). Leg dynamometer, digunakan untuk mengukur kekuatan otot tungkai. Teknik analisisi data menggunakan Uji t. Analisis statistik dengan Uji t dilakukan untuk mengetahui apakah terdapat peningkatan yang segnifikan efektifitas latihan bodyweight training dengan menggunakan metode tabata untuk meningkatkan kebugaran jasmani mahasiswa baru angkatan Tahun 2016-2017 Pendidikan Kepelatihan Olahraga FKIP Universitas PGRI Adibuana Surabaya. Setelah dilakukan analisis data maka hasil yang diperoleh menunjukkan bahwa Ho diterima, hal itu dikarena -6,99192 < 2,04523, maka Ho diterima.Kesimpulan yang didapat pada tabel di atas adalah t Stat adalah Fh (F hitung) yaitu 6,99192 dengan t Critical two-tail (t-tabel) yaitu 2,04523. Data di atas menunjukkan bahwa Ho diterima, artinya latihan bodyweight dengan metode Tabata efektif untuk meningkatkan kebugaran jasmani Mahasiswa PKO FKIP Universitas PGRI Adibuana Surabaya. Berdasasrkan hasil analisis data dan pembahasan maka dapat disimpulkan bahwa, latihan bodyweight dengan metode Tabata dapat meningkatkan kebugaran jasmani Mahasiswa PKO FKIP Universitas PGRI Adi Buana Surabaya.

Kata Kunci: Bodyweight Training, Metode Tabata, Kebugaran Jasmani

\section{PENDAHULUAN}

Kebugaran jasmani dapat diartikan sebagai kemampuan tubuh seseorang untuk melakukan tugas pekerjaan seharihari, tanpa menim-bulkan kelelahan yang berarti (Nurhasan, 2011: 12). Jadi dapat dijabarkan bahwa kebugaran jasmani berkaitan erat dengan kemampuan tubuh seseorang dalam menjalankan kelangsungan hidupnya untuk melakukan aktifitas sehari-hari dengan maksimal.

Hasil penelitian Annas M. (2014: 06) menyimpulkan bahwa rata-rata tingkat kebugaran mahasiswa Pendidikan Jasmani dan Rekreasi (PJKR) termasuk dalam kategori sedang. Hal itu dapat dijadikan

referensi untuk melakukan kajian penelitian terhadap kondisi kebugaran jasmani mahasiswa Pendidikan Kepelatihan Olahraga Universitas PGRI Adibuana Surabaya. Selain itu sebagai mahasiswa Pendidikan Kepelatihan Olahraga harus memiliki dan mampu menjaga kebu-garan jasmani mengingat mata kuliah yang dihadapi tidak hanya di kelas akan tetapi juga di luar kelas. Dengan padatnya aktivitas perkuliahan tersebut tentunya waktu yang digunakan untuk menjaga kebugaran jasmani mereka berkurang. Mahasiswa melakukan 
aktivitas fisik hanya pada jadwal perkuliahan dan tidak dapat maksimal. Maka dengan kondisi seperti itu, alternatif aktivitas fisik untuk menjaga kebugaran jasmani dibutuhkan.

Banyak alternatif yang dapat dilakukan untuk meningkatkan kebugaran jasmani, misalnya dengan bodyweight training exercise yang dapat dilakukan di mana saja tanpa membutuhkan waktu yang banyak. Latihan bodyweight training sebenarnya sudah lama berkembang, akan tetapi kurangnya pemahaman masyarakat, khususnya para mahasiswa mengenai efektivitas dari model latihan ini sehingga jarang yang mengetahui. Jenis-jenis latihan bodyweight training sangat bervariasi dan mudah dilakukan, misalnya dengan push up, sit up, back up, dan jumping jank kita sudah dapat melakukan latihan kekuatan otot serta daya tahan paru-paru.

Latihan bodyweight training merupakan latihan yang efektif karena semua komponen otot-otot tubuh melakukan kontraksi gerakan sehingga semua otot tubuh ikut terlatih. Dengan menambahkan durasi waktu untuk membatasi semua item-item latihan bodyweight training, kita juga dapat melatih kardiovaskular pada tubuh kita. Dalam melakukan latihan bodyweight training sebagai alternatif kegiatan fisik olahraga guna meningkatkan kebugaran, tentunya dibutuhkan sebuah metode latihan agar lebih efektif serta mendapatkan hasil yang maksimal. Metode-metode yang dapat digunakan pada latihan bodyweight training di antaranya adalah latihan menggunakan metode Tabata. Latihan Tabata merupakan metode latihan yang dikembangkan untuk memperoleh hasil latihan yang maksimal dan tidak memerlukan waktu panjang pada tiap sesi latihannya.

Metode latihan Tabata berasal dari Jepang yang dikembangkan oleh Dr. Izumi Tabata seorang dokter Jepang dan seorang peneliti pada tahun 1997 (Scott C., dkk., 2015: 35). Metode latihan Tabata berbasis 
interfal dengan dengan aturan 20 detik latihan, 10 detik istirahat, dan diulang selama 4 kali. Penelitian dan metode yang dilakukan serta dikembangkan oleh Dr. Tabata ini menghasilkan kesimpulan bahwa terjadi peningkatan pada kebugaran jasmani sebesar 28\% dibandingkan dengan 1 jam latihan selama lima kali seminggu dengan intensitas sedang (Howard W., 2012: 02).

Metode Tabata dengan bodyweight training digunakan sebagai alternatif untuk aktivitas fisik agar kebugaran jasmani terjaga tanpa harus menggunakan durasi waktu yang panjang. Misalnya, jika dengan menen-tukan jenis latihan bodyweight training push up 20 detik istirahat 10 detik, kemudian squat 20 detik istirahat 10 detik, sit up 20 detik istirahat 10 detik, burpess 20 detik istirahat 10, lalu ulangi semua item latihan itu sebanyak 8 kali pada setiap sesi latihan, maka tidak akan memakan waktu sehingga aktifitas yang lain akan tetap dapat dijalankan.
Berdasarkan paparan mengenai pentingnya kebugaran jasmani dan latihan bodyweight training dengan menggunakan metode Tabata maka peneliti ingin mengkaji tentang efektivitas latihan bodyweight training dengan menggunakan metode Tabata untuk meningkatkan kebugaran jasmani mahasiswa baru angkatan 2016-2017 Pendidikan Kepelatihan Olahraga, Fakultas Keguruan Ilmu Pendidikan, Universitas PGRI Adibuana Surabaya. Melalui penelitian ini diharapkan mampu memaksimalkan dan sekaligus memberi solusi kepada mahasiswa untuk dapat selalu melakukan aktivitas fisik agar dapat meningkatkan dan menjaga kondisi kebugaran jasmani sehingga mahasiswa mampu melakukan aktivitas sehari-hari dengan maksimal dan lebih berkualitas.

\section{TINJAUAN PUSTAKA}

\section{Latihan Bodyweight training}

Bodyweight training diartikan oleh ACSM (American College of Sports Medicine) adalah suatu bentuk latihan 
dengan menggunakan beban tubuh untuk

meningkatkan kebugaran. Sedangkan

Contreras (2014) menjelaskan bahwa

bodyweight training merupakan latihan

untuk menguasai berat badan sendiri

sebelum menggunakan latihan beban. Jadi

dapat diartikan bahwa bodyweight training

merupakan suatu bentuk latihan dengan

menggunakan beban sendiri sebagai dasar

sebelum melakukan latihan dengan meng-

gunakan beban luar. Latihan bodyweight

training merupakan latihan yang dapat

dilakukan di manapun sehingga sangat

efisien dan kita dapat selalu menjaga

kebugaran jasmani tanpa harus menguras

waktu lama (Rey, 2015).

Pada prinsipnya jenis-jenis latihan

bodyweight training menurut Contreras

(2014) adalah latihan yang cenderung

mendorong dan menarik. Hal itu disesu-

aikan dengan adanya hubungan erat antara

pola gerak manusia tidak lepas dari apa

yang disebut gravitasi. Contoh gerakan la-

tihan bodyweight training misalnya squat,

lunges, push up dan sebagainya. Lebih lanjut, latihan bodyweight training memi-

liki keuntungan lebih dikarenakan, ketika

kita melakukan latihan, kita tidak perlu

ketergantungan dengan spotter.

\section{Metode Latihan Tabata}

Metode latihan Tabata berasal dari Jepang yang dikembangkan oleh Dr. Izumi Tabata seorang dokter Jepang dan seorang peneliti pada tahun 1997 (Scott C., dkk., 2015: 35). Metode latihan Tabata berbasis interfal dengan dengan aturan 20 detik latihan 10 detik istirahat dan diulang selama 4 kali. Penelitian telah membuktikan bahwa terjadi peningkatan $\mathrm{VO}_{2}$ max sebesar $28 \%$ hanya dengan latihan selama 6 minggu dengan intensitas tinggi yang terbagi menjadi 20 detik latihan 10 detik istirahat dan diulang hingga 8 set (Tabata, 1996).

Penelitian serupa dilakukan oleh Howard W. (2012: 02) dengan membandingkan antara penggunaan metode Tabata dengan latihan tradisional. Temuan dari penelitian Howard W. membuktikan bahwa penggunaan kettlebell swing 
dengan metode Tabata berbasis interval dapat me-ningkatkan kardiovaskular dan metabolic demands lebih tinggi dibandingkan latihan dengan metode tradisional.

Metode latihan Tabata menggunakan high intensity interval training (HIIT) telah terbukti dengan cepat meningkatkan kebugaran (Scott, 2015: 35). Metode pelatihan menggunakan Tabata sangat efektif untuk meningkatkan proses metabolisme. Jika tubuh diberikan intensitas tinggi maka kondisi jantung akan dengan cepat memompa darah sehingga metabolisme tubuh dengan cepat akan naik (Flavia, 2015).

Banyak variasi untuk mela-kukan latihan bodyweight dengan metode Tabata. Desain program latihan bodyweight training dengan metode Tabata dapat kita ambil dari contoh desain program dari BTS (Bodyweight Training System) 2011 sesi latihan dari pemanasan, inti, hinga pen-dinginan. Program ini dapat disesuaikan dengan kondisi denyut nadi maksimal (DNM).

\section{Kebugaran Jasmani}

Kebugaran jasmani dalam bahasa asing disebut physical fitness. Kebugaran jasmani didefinisikankan sebagai kemampuan tubuh seseorang untuk melakukan tugas pekerjaan sehari-hari tanpa menimbulkan kelelahan yang berarti (Nurhasan, 2011: 12). Sedangkan menurut tokoh Pendidikan Jasmani yaitu Cholik dan Maksum (2007: 51) mengemukakan bahwa kebugaran jasmani adalah kesanggupan tubuh untuk melakukan aktivitas tanpa mengalami kelelahan yang berarti. Seorang John F. Kennedy mengatakan bahwa, kebugaran jasmani merupakan bagian terpenting sebagai kunci kesehatan tubuh, serta dasar aktivitas yang dinamis, kreatif, dan cerdas (Nurhasan, 2011: 13). Maka, dapat disimpulkan bahwa kebugaran jasmani merupakan wujud ketahanan fisik seseorang untuk melakukan aktivitas 
sehari-hari tanpa mengalami kelelahan yang berarti sehingga seseorang mampu menjalani aktivitasnya dengan dinamis, kreatif dan cerdas.

Lebih jauh Sudarsono (2008: 02) menerangkan bahwa, kondisi kebugaran seseorang merupakan salah satu faktor yang menentukan tingkat kesehatannya. Hal itu didasarkan pada bagaimana kemampuan seseorang untuk dapat menjaga kekuatan jantung dan paru-paru dengan baik sehingga semua sistem tubuh mampu menyerap oksigen dengan optimal. Ketika oksigen dapat diserap oleh sistem tubuh melalui paru-paru kemudian diteruskan oleh jantung dan pembuluh darah untuk didistribusikan ke seluruh tubuh. Maka dari itu kemampuan jantung dan paru-paru tersebut merupakan salah satu komponen yang harus diperhatikan oleh seseorang agar selalu dalam kondisi bugar.

Komponen kebugaran berikutnya adalah berkaitan dengan kebugaran otot yang meliputi daya tahan otot serta kekuatan otot. Daya tahan otot dapat diartikan sebagai kemampuan otot dalam melakukan kontraksi otot baik statis maupun dinamis (Kusnanik, 2011: 121). Daya tahan otot dapat dili-hat dari bagaimana seseorang mampu melakukan gerakan yang bersifat statis maupun dinamis, misalnya kita melakukan latihan sit up, push up, atau dalam melakukan aktivitas sehari-hari dengan maksimal. Selanjutnya menurut Kusnanik (2011: 121) menerangkan bahwa kekuatan otot dapat didefini-sikan sebagai gaya (force) yang dihasilkan oleh sebuah otot atau kelompok otot. Hal itu dapat dijabarkan bawah kekuatan otot dapat dilihat dari kemam-puan otot dalam menghasilkan gaya untuk aktivitas keseharian.

Komposisi tubuh merupakan karakteristik tubuh seseorang (anthropometri) yang meliputi tinggi badan, berat badan, panjang lengan, panjang tungkai, serta ketebalan lemak (Fenanlampir dan Faruq, 2014: 30-31). Hal itu dapat kita jabarkan bahwa untuk menjaga kebugaran jasmani, selain menjaga daya tahan kardio- 
vaskuler serta kekuatan dan dayactahan otot maka komposisi tubuh agar selalu ideal sesuai dengan karakteristik tubuh seseorang harus tetap terjaga agar kualitas fisiologis maupun mental kita tetap bugar.

Kondisi kebugaran jasmani pada seseorang dipengaruhi oleh dua faktor utama yaitu, faktor internal dan eksternal (Nurhasan, 2011: 19). Faktor internal antara lain genetik, umur dan jenis kelamin, sedangkan faktor eksternal meliputi aktifitas fisik, status gizi dan status kesehatan. Hasil penelitian Sandvik L., dkk (1996) menyimpulkan bahwa faktor ekster-nal meliputi gaya hidup sehat, sedangkan kebiasaan merokok sangat mempengaruhi faktor kebugaran jasmani internal. Hasil penelitian itu bisa diartikan bahwa kebu-garan jasmani sangat berkaitan dengan faktor internal dan eksternal. Kedua faktor tersebut sangat berhubungan dan saling menguatkan ketika kita dapat menjaga kedua faktor yang mempengaruhi kebu-garan jasmani tersebut.

\section{METODE PENELITIAN}

Penelitian ini menggunakan eksperimen dengan desain penelitian yang digunakan dalam penelitian yaitu one groups pre-test - post-test design, desain penelitian yang terdapat pre-test sebelum diberi perla-kuan dan post-test setelah diberi perlakuan. Dalam hal ini yang diukur adalah tingkat kebugaran jasmani mahasiswa baru ang-katan 2016-2017 Pendidikan Kepelatihan Olahraga FKIP Universitas PGRI Adibuana Surabaya sebagai Populasi dan sampel. Sampel penelitian diambil menggunakan simple random sampling mengingat semua mahasiswa baru berpeluang menjadi sampel dalam penelitian. Instrumen yang digunakan dalam penelitian ini untuk mendapatkan data yang valid meliputi: MFT (Multistage Fitness Test) untuk mengukur oksigen maksimal atau $\mathrm{VO}_{2}$ max, sit up, pull up, grip strength test, back dynamometer, leg dynamometer. 
Untuk memperoleh kesimpulan hasil penelitian yang disahkan dalam penelitian ini, diper-lukan metode analisis statistik yaitu dengan menggunakan Uji-t. Uji-t ini disebut the one group desain yang bertujuan untuk mengetahui efektivitas treatment apakah terdapat peningkatan yang signifikan efek-tivitas latihan bodyweight training dengan menggunakan metode Tabata untuk me-ningkatkan kebugaran jasmani mahasiswa baru angkatan Tahun 2016-2017 Pendi-dikan Kepelatihan Olahraga FKIP Univer-sitas PGRI Adibuana Surabaya.

\section{HASIL DAN PEMBAHASAN}

\section{Hasil Penelitian}

Setelah melakukan serangkaian kegiatan penelitian tersebut memperoleh gambaran data hasil tes sebagai berikut:

a. Nilai pre-test dan post-test berat badan

Hasil tes menunjukkan bahwa tidak ada perubahan berat badan baik sebelum dan sesudah mahasiswa melakukan latihan bodyweight dengan metode Tabata karena berat badan maksimum pada saat pre-test dan posttest masih tetap yaitu $85 \mathrm{~kg}$ dan berat badan minimum juga tetap, yaitu 42 kg. Tidak adanya perubahan berat badan pada mahasiswa yang mengikuti treatment juga didukung dengan ratarata dan standar deviasi berat badan pada saat pre-test dan post-test tetap, yaitu $60,07 \mathrm{~kg}$ dan $10,80 \mathrm{~kg}$. Dengan demikian dapat disimpulkan bahwa treatment yang diberikan pada mahasiswa tidak memengaruhi berat badan mahasiswa.

b. Nilai pre-test dan post-test tinggi badan

Hasil tes menunjukkan bahwa tidak ada perubahan tinggi badan pada mahasiswa yang mengikuti treatment, yang juga didukung dengan rata-rata dan standar deviasi tinggi badan pada saat pre-test dan post-test tetap, yaitu $166,73 \mathrm{~cm}$ dan 7,01 cm. Dengan demikian dapat disimpulkan bahwa treatment yang diberikan pada maha- 
siswa tidak mempengaruhi tinggi badan mahasiswa.

c. Nilai pre-test dan post-test MFT (Multistage Fitness Test)

Hasil MFT maksimum sampel pada saat pre-test dan post-test yaitu $46,3 \mathrm{ml} / \mathrm{kg} / \mathrm{min}$ menjadi 49,3 $\mathrm{ml} / \mathrm{kg} / \mathrm{min}$ dan hasil MFT minimum sampel juga meningkat, yaitu 25,6 $\mathrm{ml} / \mathrm{kg} / \mathrm{min}$ menjadi $30,2 \mathrm{ml} / \mathrm{kg} / \mathrm{min}$. Peningkatan hasil MFT sampel yang mengikuti treatment juga didukung dengan rata-rata dan standar deviasi hasil MFT pada saat pre-test dan posttest meningkat, yaitu $33,75 \mathrm{ml} / \mathrm{kg} / \mathrm{min}$ menjadi $39,83 \mathrm{ml} / \mathrm{kg} / \mathrm{min}$ dan 6,77 $\mathrm{ml} / \mathrm{kg} / \mathrm{min}$ menjadi $5,99 \mathrm{ml} / \mathrm{kg} / \mathrm{min}$. Secara keseluruhan rata-rata peningkat-an MFT Mahasiswa PKO FKIP Univer-sitas PGRI Adibuana Surabaya sebelum dan sesudah dilakukan latihan body-weight dengan metode Tabata, yaitu sebesar 20,13\%. Dengan demikian dapat disimpulkan bahwa treatment yang diberikan pada mahasiswa dapat meningkatkan hasil MFT mahasiswa.

d. Nilai pre-test dan post-test daya tahan otot - sit up

Terjadi peningkatan hasil tes sit up mahasiswa antara sebelum dengan sesudah mahasiswa melakukan latihan bodyweight dengan metode Tabata karena hasil tes sit up maksimum sampel pada saat pre-test dan post-test yaitu 48 kali menjadi 53 kali dan hasil tes sit up minimum sampel juga meningkat, yaitu 32 kali menjadi 37 kali. Peningkatan hasil tes sit up sampel yang mengikuti treatment juga didukung dengan rata-rata hasil tes sit up pada saat pre-test dan post-test meningkat, yaitu 41,80 kali menjadi 47,47 kali. Standar deviasi hasil tes sit up antara sebelum dan sesudah pemberian treat-ment juga meningkat yaitu sebesar 5,12 kali menjadi 5,23 kali. Secara keselu-ruhan rata-rata peningkatan hasil tes sit up Mahasiswa PKO FKIP Universitas PGRI 
Adibuana Surabaya sebelum dan sesudah dilakukan latihan bodyweight dengan metode Tabata, yaitu sebesar 14,12\%. Dengan demikian dapat disim-pulkan bahwa treatment yang diberikan pada mahasiswa dapat meningkatkan hasil tes sit up mahasiswa.

e. Nilai pre-test dan post-test daya tahan otot - pull up

Hasil tes menunjukkan bahwa terjadi peningkatan hasil tes pull up mahasiswa antara sebelum dengan sesudah mahasiswa melakukan latihan bodyweight dengan metode Tabata karena hasil tes pull up maksimum sampel pada saat pre-test dan pos-ttest yaitu 48 kali menjadi 53 kali tetapi hasil tes pull up minimum sampel tetap, yaitu 4 kali. Akan tetapi, peningkatan hasil tes pull up sampel yang mengikuti treatment didukung dengan rata-rata hasil tes pull up pada saat pre-test dan post-test meningkat, yaitu 8,17 kali menjadi 10,23 kali dan standar deviasi hasil tes pull up antara sebelum dan sesudah pemberian treatment juga meningkat yaitu sebesar 2,38 kali menjadi 3,20 kali. Secara keseluruhan rata-rata hasil tes pull up Mahasiswa PKO FKIP Universitas PGRI Adibuana Surabaya sebelum dan sesudah dilakukan latihan body-weight dengan metode Tabata, yaitu sebesar $28,48 \%$.

f. Nilai pre-test dan post-test kekuatan otot grip strength (tangan kanan dan kiri)

Hasil tes grip strength tangan kiri maksimum sampel pada saat pretest dan post-test yaitu 46,6 kg menjadi $51,6 \mathrm{~kg}$ dan hasil tes grip strength tangan kiri minimum sampel juga meningkat, yaitu $22 \mathrm{~kg}$ menjadi $25 \mathrm{~kg}$. Peningkatan hasil tes grip strength tangan kiri sampel yang mengikuti treatment didukung dengan rata-rata hasil tes grip strength tangan kiri pada saat pre-test dan post-test meningkat, yaitu $38,75 \mathrm{~kg}$ menjadi $41,74 \mathrm{~kg}$. Akan 
tetapi, standar deviasi hasil tes grip strength tangan kiri antara sebelum dan sesudah pemberian treatment menurun yaitu $9,55 \mathrm{~kg}$ menjadi $9,17 \mathrm{~kg}$. Secara keseluruhan rata-rata hasil tes grip strength tangan kiri Mahasiswa PKO FKIP Universitas PGRI Adibuana Surabaya sebelum dan sesudah dilakukan latihan bodyweight dengan metode Tabata, yaitu sebesar 9,61\%.

Pada tes grip strength tangan kanan hasil tes menunjukkan maksimum sampel pada saat pre-test dan post-test yaitu 46,6 kg menjadi $51,5 \mathrm{~kg}$ dan hasil tes grip strength tangan kanan minimum sampel juga meningkat, yaitu $22 \mathrm{~kg}$ menjadi $25 \mathrm{~kg}$. Peningkatan hasil tes grip strength tangan kanan sampel yang mengikuti treatment didukung dengan rata-rata hasil tes grip strength tangan kanan pada saat pre-test dan post-test meningkat, yaitu $37,32 \mathrm{~kg}$ menjadi 41,39 kg. Standar deviasi hasil tes grip strength tangan kanan antara sebelum dan sesudah pemberian treatment juga meningkat yaitu 9,15 kg menjadi 9,21 $\mathrm{kg}$.

g. Nilai pre-test dan post-test kekuatan otot back dynamometer

Hasil tes back dynamometer maksimum sampel pada saat pre-test dan post-test yaitu $88,8 \mathrm{~kg}$ menjadi 113,59 kg dan hasil back dynamometer minimum sampel juga meningkat, yaitu $50,7 \mathrm{~kg}$ menjadi $70,7 \mathrm{~kg}$. Peningkatan hasil back dynamometer sampel yang mengikuti treatment didukung dengan rata-rata hasil back dynamometer pada saat pre-test dan post-test meningkat, yaitu $71,05 \mathrm{~kg}$ menjadi 92,75 kg. Akan tetapi, standar deviasi hasil tes back dynamometer antara sebelum dan sesu-dah pemberian treatment menurun yaitu $10,85 \mathrm{~kg}$ menjadi $9,99 \mathrm{~kg}$. Secara keseluruhan rata-rata hasil tes back dynamometer Mahasiswa PKO FKIP Universitas PGRI Adibuana Surabaya sebelum dan sesudah dilakukan latihan 
bodyweight dengan metode Tabata, yaitu sebesar 31,55\%.

\section{h. Nilai Pre-test dan Post-test Kekuatan}

\section{Otot Leg Dynamometer}

Hasil tes leg dynamometer maksimum sampel pada saat pre-test dan post-test yaitu $180 \mathrm{~kg}$ menjadi 200 $\mathrm{kg}$ dan hasil leg dynamometer minimum sampel juga meningkat, yaitu $145,33 \mathrm{~kg}$ menjadi $165,33 \mathrm{~kg}$. Peningkatan hasil leg dynamometer sampel yang mengikuti treatment juga didukung dengan rata-rata hasil leg dynamo-meter pada saat pre-test dan post-test meningkat, yaitu $160,13 \mathrm{~kg}$ menjadi $180,13 \mathrm{~kg}$. Namun standar deviasi hasil leg dynamometer antara sebelum dan sesudah pemberian treatment tetap yaitu sebesar 49,34 kg. Secara keselu-ruhan rata-rata peningkatan hasil leg dynamometer Mahasiswa PKO FKIP Universitas PGRI Adibuana Surabaya sebelum dan sesudah dilakukan latihan bodyweight dengan metode Tabata, yaitu sebesar $12,53 \%$.

Berdasarkan hasil data tersebut dapat disajikan persentase peningkatan pada tiap-tiap variabel penelitian pada tabel 1 .

Tabel 1. Hasil Persentase Peningkatan

\section{Variabel Tes Persentase \\ Peningkatan}

(\%)

\begin{tabular}{ll}
\hline Berat Badan & 0 \\
Tinggi Badan & 0 \\
\hline MFT & 20,13 \\
Sit Up & 14,12 \\
Pull Up & 28,48 \\
Grip Strength-Left & 9,61 \\
$\begin{array}{l}\text { Grip Strength- } \\
\text { Right }\end{array}$ & 11,67 \\
$\begin{array}{l}\text { Back } \\
\text { Dynamometer }\end{array}$ & 31,55 \\
\hline Leg Dynamometer & 12,53 \\
\hline
\end{tabular}

Berikutnya, untuk menjawab hipotesis penelitian, maka dilakukan uji-t setelah semua syarat uji telah terpenuhi. Uji hipotesis dilakukan dengan metode statistika uji-t, yang bila nilai signifikasi variabel penelitian lebih kecil dari 0,05 maka $\mathrm{H}_{\mathrm{o}}$ ditolak dan $\mathrm{H}_{\mathrm{a}}$ diterima, namun apabila lebih besar dari $0,05 \mathrm{H}_{\mathrm{o}}$ di terima dan $\mathrm{H}_{\mathrm{a}}$ ditolak. Hasil pengujian yang telah 
dilakukan peneliti akan disajikan dalam tabel 2.

Jika Fh $<$ Ft maka $\mathrm{H}_{\mathrm{o}}$ diterima, hal itu dikarenakan $-6,99192<$ 2,04523, maka $\mathrm{H}_{\mathrm{o}}$ diterima. Kesimpulan yang didapat pada tabel 2, t Stat adalah Fh (F hitung) yaitu 6,99192 dengan t Critical two-tail (t-tabel) yaitu 2,04523. Data di atas menunjukkan bahwa $\mathrm{H}_{\mathrm{o}}$ diterima, artinya latihan bodyweight dengan metode Tabata efektif untuk meningkatkan kebugaran jasmani Mahasiswa PKO FKIP Universitas PGRI Adibuana Surabaya.

Tabel 2. Uji-t

\begin{tabular}{lll}
\hline t-Test: Paired Two Sample for Means & \\
\hline & Pre-test & Post-test \\
\hline Mean & 33,74667 & 39,83 \\
\hline Variance & 45,7874 & 35,90769 \\
\hline Observations & 30 & 30 \\
Pearson Correlation & 0,727357 & \\
\hline Hypothesized Mean Difference & 0 & \\
Df & 29 & \\
t Stat & $\mathbf{- 6 , 9 9 1 9 2}$ & \\
P(T<=t) one-tail & $5,47 \mathrm{E}-08$ & \\
t Critical one-tail & 1,699127 & \\
\hline P(T<=t) two-tail & $1,09 \mathrm{E}-07$ & \\
$\mathbf{t}$ Critical two-tail & $\mathbf{2 , 0 4 5 2 3}$ \\
\hline
\end{tabular}

\section{PEMBAHASAN}

Persentase peningkatan yang ditunjukkan pada tes $M F T$, yaitu sebesar $20,13 \%$ dengan peningkatan rata-rata hasil MFT yang diperoleh sampel yaitu meningkat sebesar $6,08 \mathrm{ml} / \mathrm{kg} / \mathrm{min}$, yang awalnya sebesar $33,75 \mathrm{ml} / \mathrm{kg} / \mathrm{min}$ menjadi $39,83 \mathrm{ml} / \mathrm{kg} / \mathrm{min}$. Persentase peningkatan yang ditunjuk-kan pada tes grip strength, yaitu sebesar 9,61\% (left hand) dan 11,67 
(right hand) dengan peningkatan rata-rata hasil tes grip strength-left yang diperoleh sampel yaitu meningkat sebesar $2,99 \mathrm{~kg}$, yang awalnya sebesar $38,75 \mathrm{~kg}$ menjadi $41,74 \mathrm{~kg}$ dan peningkatan rata-rata hasil tes grip strength-right yang diperoleh sampel yaitu meningkat sebesar 4,07 kg, yang awalnya sebesar $37,32 \mathrm{~kg}$ menjadi 41,39 kg. Di samping itu, juga terdapat pening-katan pada hasil pengukuran kekuatan otot punggung sampel yang dilakukan dengan back dynamometer.

Persentase peningkatan kekuatan otot punggung diperoleh sebesar $31,55 \%$ dengan besar peningkatan rata-ratanya adalah sebesar $21,7 \mathrm{~kg}$, yang mana ratarata awalnya sebesar $71,05 \mathrm{~kg}$ menjadi $92,75 \mathrm{~kg}$. Selain itu, juga terdapat peningkatan pada hasil pengukuran kekuatan otot tungkai sampel yang dilakukan dengan menggunakan leg dynamometer. Persen-tase peningkatan kekuatan otot tungkai diperoleh sebesar $12,53 \%$ dengan besar pening-katan rataratanya adalah sebesar $20 \mathrm{~kg}$, yang mana rata-rata awalnya sebesar 160,13 kg menjadi $180,13 \mathrm{~kg}$.

Dengan demikian dapat disimpulkan bahwa latihan bodyweight dengan metode Tabata dapat meningkatkan kebugaran jasmani Mahasiswa PKO FKIP Universitas PGRI Adibuana Surabaya karena setelah Mahasiswa PKO FKIP Universitas PGRI Adibuana Surabaya melakukan latih-an bodyweight dengan metode Tabata, hasil MFT, tes sit up, tes pull up, grip strength, back, dan leg dynamometer mereka meningkat secara signifikan.

\section{KESIMPULAN DAN SARAN}

Berdasarkan hasil analisis data dan pembahasan maka dapat disimpulkan bahwa, latihan bodyweight dengan metode Tabata dapat meningkatkan kebugaran jasmani Mahasiswa PKO FKIP Universitas PGRI Adibuana Surabaya. Setelah Maha-siswa PKO FKIP Universitas PGRI Adibuana Surabaya melakukan latihan bodyweight dengan metode Tabata, hasil MFT, tes sit up, tes 
pull up, grip strength, back dan leg dynamometer mereka mening-kat secara signifikan.

Kebugaran sangat dibutuhkan bagi tubuh manusia, tidak terkecuali mahasiswa. Sebagai usaha dalam menjaga dan mening-katkan kebugaran maka disarankan untuk seluruh selalu melakukan aktivitas fisik. Sebagai alternatif latihan yang dapat dilakukan mahasiswa diselasela kesibuk-annya yaitu latihan bodyweight training dengan metode Tabata. Metode latihan yang efektif dan dapat dilakukan di mana saja yang memberikan warna baru dalam usaha menjaga dan meningkatkan kebugar-an, khususnya bagi Mahasiswa Pendidikan Kepelatihan Olahraga FKIP Universitas PGRI Adibuana Surabaya.

\section{DAFTAR PUSTAKA}

American College of Sports Medicine. (2008). ACSM's health-related physical fitness assessment manual. Philadelphia' Baltimore' New York' London' Buenos Aires' Hong Kong' Sydney' Tokyo. Handbook.

Boutcher, S.H. (2011). High-intensity intermittent exercise and fat loss. $\mathrm{J}$
Obes. Published online Nov $24^{\text {th }}$, 2010.

http://www.ncbi.nlm.nih.gov/pmc/ articles/PMC2991639/. Diakses 15 Mei 2016.

BTS, CF Fitness Anytime, Anywhere. (2011). Bodyweighty training system. $\quad$ www.DFIT.ca. http://www.cfmws.com/en/AboutU s/PSP/DFIT/Fitness/BTS\%20Docu ment\%20Library/ENG\%20BTS.pd f. Diakses 27 Mei 2016.

Contreras, B. (2014). Bodyweight strength training anatomy: your illustrated gide to strength, power and definition. www.HumanKinetics.com. Diakses 02 Mei 2016.

Fenanlampir, A. Faruq, M. (2014). Tes dan pengukuran dalam olahraga. $\mathrm{CV}$. Andi Offset.

Howard M. (2012). Fitness: Tabata interval training. Richmond Times-Dispatch, Published: June $03^{\text {rd }}, 2012$.

Kementerian Pemuda dan Olahraga (2014). Jurnal olahraga pendidikan. Asisten Deputi Olahraga Pendidikan Deputi Bidang Pembudayaan Olahraga Kementrian Pemuda dan Olahraga Republik Indonesia. Jakarta.Vol 1.No,1 Mei 2014.ISSN: 23557036.

Kusnanik, W.K., dkk. (2011). Dasar-dasar fisiologi olahraga. Surabaya: Unesa University Pers.

Mahardika, I.M.S. (2010). Pengantar evaluasi pengajaran. Unesa University Press. 
Maksum, A. (2012). Metodologi penelitian dalam olahraga. Surabaya: Unesa University Press.

Nurhasan, (2011). Tips praktis menjaga kebugaran jasmani. Gresik: Abil Pustaka.

Scott C., dkk. (2015). Total energy costs of Tabata-type calisthenic squatting routines: isometric, isotonic and jump. Department of Exercise, Health and Sport Sciences. University of Southern Maine. European Journal of Human Movement, 2015: 35, 34-40.

Rey N. (2015). 100 no-equipment workouts. Handbook. Derebeta.com.

Sandvik, L. Erikssen, J., Thaulow, E., dkk. (1996). Physical fitnesss as a predictor of mortality among healthy, middle-aged Norwegian men. The New England Journal Of Medicine. Vol. 328 No.8. Downloaded from nejm.org on
May 25th, 2016. For personal use only. No other uses without permission. Copyright (C) 1993 Massachusetts Medical Society. All rights reserved. Diakses $25 \mathrm{Mei}$ 2016.

Sudarsono, N.C (2008). Kuliah pengantar pada kelas Foundation, Mata Kuliah Fitness and Art. http://staff.ui.ac.id/system/files/use rs/nani.cahyani/material/kebugaran .pdf. Diakses 20 Mei 2016

Tabata I., Nishimura K., Kouzaki M., Hirai Y., Ogita F., Miyachi M., dan Yamamoto K. (1996). Effects of moderate-intensity endurance and high-intensity intermittent training on anaerobic capacity and VO2 max. Journal Medicine \& Science in Sports \& Exercise: October 1996 - Volume 28 - Issue 10 - pp 1327-1330.

Dari http://journals.lww.com/acsm msse/Abstract/1996/10000/Effects _of_moderate_intensity_endurance _and.18.aspx. Diakses 24 Mei 2016 